\title{
POLÍTICA, RELIGIÓN Y RACIALIDAD EN SUDÁFRICA CONTEMPORÁNEA
}

\author{
POLÍTICA, RELIGIÃO E RACIALIDADE NA ÁFRICA DO SUL CONTEMPORÃNEA
}

\author{
Eugenia Arduino \\ Universidad de Buenos Aires - UBA
}

\section{Resumen}

El tema de la presente investigación se centra en las características del proceso de interrelación entre sectores políticos y las principales vertientes cristianas protestantes de la República de Sudáfrica, desde mediados del siglo XX hasta el presente. Los autores que tangencialmente lo habían tratado, eludían ahondar en cuestiones socio culturales, en el impacto ocasionado, y en el papel desempeñado por los actores más vulnerables. Las justificaciones explicativas hasta los años '80 casi lo naturalizaban como una forma política más, a la vez que sólo unos pocos escritos superaban la censura sudafricana y exponían una parte de la dramática trama local. Desde entonces, la desigualdad institucionalizada durante décadas, basada en criterios raciales, comenzó a ser estudiada desde diferentes ámbitos disciplinares, por lo cual, con el fin de obtener como resultado un conocimiento interpretativo / analítico / explicativo, fue investigada la presencia de cuatro vertientes cristianas protestantes en Sudáfrica, particularizando en las instancias de reelaboración producidas a partir de la diversidad etnorreligiosa local, para comprender el modo a través del cual aquellas se interrelacionaron con los representantes políticos desde la segunda mitad del siglo XX y hasta el presente. El principal objetivo buscó comprender los mecanismos a partir de los cuales las ideas y prácticas, tanto políticas como de las vertientes religiosas estudiadas en Sudáfrica, utilizaron argumentos teológicos como forma de legitimación sobre sistemas ideológicos y políticos impuestos a la sociedad, tanto en el caso represivo del apartheid, como en la resistencia antiapartheid. Tal sistema fue instaurado en $1948 \mathrm{y}$ 
devino en el control total de la población blanca, creando fronteras internas, racializando y despolitizando a la mayoría no blanca. Las vertientes protestantes actuaron en general, legitimándolo, evitando confrontaciones por medio de una tácita neutralidad, o bien otorgando argumentos para la resistencia antiapartheid.

Palabras clave: Política. Religión. Racialidad. Apartheid. Sudáfrica.

\section{Resumo}

O tema desta pesquisa enfoca as características do processo de inter-relação entre setores políticos e os principais aspectos cristãos protestantes da República da África do Sul, desde meados do século XX até o presente. Os autores que trataram-no tangencialmente escaparam às questões socioculturais, ao impacto causado e ao papel desempenhado pelos atores mais vulneráveis. Justificativas explicativas até a década de 1980 quase a naturalizaram como apenas mais uma forma política, enquanto apenas alguns escritos excederam a censura sul-africana e expuseram uma parte da dramática trama local. Desde então, a desigualdade institucionalizada por décadas, baseada em critérios raciais, passou a ser estudada a partir de diferentes áreas disciplinares, de modo que, para obter como resultado um conhecimento interpretativo/analítico/explicativo, investigou-se a presença de quatro aspectos cristãos. Protestantes na África do Sul, particularizando-se nas instâncias de reprocessamento produzidas a partir da diversidade étnico-religiosa local, para compreender a maneira como esses se inter-relacionavam com os representantes políticos da segunda metade do século $\mathrm{XX}$ até o presente. $\mathrm{O}$ objetivo principal buscou compreender os mecanismos do que idéias e práticas, tanto políticas como religiosas estudadas na África do Sul, usaram argumentos teológicos como uma forma de legitimação em sistemas ideológicos e políticos impostos à sociedade, tanto no caso repressivo do apartheid, quanto na resistência anti-apartheid. Este sistema foi criado em 1948 e tornou-se o controle total da população branca, criando fronteiras internas, racializando e despolitizando a maioria não branca. Os declives protestantes agiram 
em geral, legitimando-os, evitando confrontos por meio de uma neutralidade tácita, ou concedendo argumentos para a resistência anti-apartheid.

Palavras-chave: Política. Religião. Racialidade. Apartheid. África do Sul.

\section{Introducción}

Desde comienzos del siglo XX se ha asistido a la persistencia, a la diversificación y a la reelaboración de experiencias de religiosidad, entendidas como expresión de cambios en la cualidad de lo religioso - espiritual. África no fue una excepción en tal proceso, protagonizado por sus habitantes en el marco de complejos desafíos locales. Los enunciados que históricamente habían tenido presencia en el continente junto con los propuestos por quienes expandieron allí las adscripciones cristianas protestantes desde el siglo XVII atravesaron por situaciones de resignificación tales que condujeron a un renovado y dinámico escenario hacia lo espiritual. Además del mensaje bíblico, las experiencias de misionalización difundieron mecanismos culturales diversos que, con el tiempo, fueron incorporados selectivamente por la población local, a partir de una reelaboración que produjo como resultado el surgimiento de un cristianismo contextualizado en África.

En el territorio de la actual Sudáfrica, específicamente, aquella religión estuvo presente desde 1665 por medio de la adscripción reformada. Más tarde se sumaron otras, entre las que se destacaron la anglicana, la metodista y la pentecostal. Las cuatro llevaron a cabo su práctica misional diferenciándose en sus organizaciones e ideas. Las comunidades locales, por su parte, vivieron tal difusión como una situación de dramatismo que irrumpió en sus cosmovisiones y derivó en procesos de estandarización de imaginarios, de discursos y de simbolismos. De ese modo, se sumaron / impusieron nuevas realidades a un contexto de por sí multiforme, en el que el protestantismo se fue redimensionando paulatinamente.

El poder político, liderado por una minoría blanca, implementó, desde principios del siglo XX y de modo paulatino, una férrea segregación basada en criterios raciales hacia la población no blanca. La aplicación institucionalizada de aquélla derivó en la consolidación en 
1948 del sistema de apartheid, vigente hasta 1994. En ese escenario, la vertiente protestante reformada sustentó justificaciones teológicas de la racialización esgrimida desde el gobierno, mientras que las demás, y en el sentido opuesto, expresaron enunciados tendientes al cuestionamiento de tal principio y de sus derivaciones, o bien, evitaron tomar posición sobre el tema. La realidad sudafricana evidenció entonces múltiples cruces, interrelaciones y rupturas que caracterizaron los vínculos entre la religión y la política. Los diferentes actores que operaron a partir de ellos se expresaron por medio de discursos y prácticas que actuaron como mecanismos de articulación, oscilantes en el tiempo.

En el marco de lo expuesto, el recorrido realizado a lo largo de la investigación que se presenta se focalizó en la relación política - religión protestante en Sudáfrica desde el siglo XX y hasta el presente como problema central. Dada la manifiesta interdependencia entre tales áreas, se consideró importante comprender el modo en que operaron las instancias de control y justificación basadas alternativamente, en retóricas religionalizantes de la política o, en su contracara, politizantes de la religión. En esa dinámica, el conjunto social y los sujetos se hallaban inmersos y comprometidos de modo ineludible. De allí que haya resultado pertinente conocer las dimensiones que se desplegaron a partir de los alegatos y las acciones, creadoras de la realidad en la que aquéllos debieron transitar su devenir.

La elección del tema, surgida a partir de la detección en investigaciones previas sobre tópicos históricos sudafricanos de un conjunto de vínculos entre política y religión que no aparecían expresados en la producción académica, motivó la realización de un trabajo que diera cuenta de las interacciones entre ambas. Sumado a ello, el campo religioso contemporáneo ha evidenciado procesos de religionalización de la política que, a diferencia de los del pasado, devinieron en polifacéticos escenarios signados por heterogéneas disputas de impacto translocal. En el sentido contrario, la politización religiosa condicionó alianzas, rivalidades y oscilantes interjuegos de poder que trascendieron la mera dialéctica espiritual.

Por lo antedicho, investigar la relación entre la política y la religión en Sudáfrica contemporánea resultó relevante por tratarse de un caso en el cual los mecanismos de articulación generados por las prácticas religiosas y los discursos políticos podrían devenir en indicadores o categorías de análisis aptos para indagar otros escenarios en los cuales se presuma una imbricación similar. Además, en el caso sudafricano, especie de laboratorio de mecanismos de sociabilidad, la redimensión de ideas y acciones de sus actores políticos y 
religiosos en profunda interrelación, pudo ofrecer escenarios de integración que aún continúan en proceso.

Las vertientes cristianas protestantes indagadas - reformada, anglicana, metodista y pentecostal - y el poder, en su expresión política, del Partido Nacional, fueron analizadas para comprender el conjunto de heterogéneas estrategias que condujeron a sus actores, individuales e institucionales, a expresar fundamentaciones discursivas tanto de apoyo al gobierno como de resistencia y / o de diplomática indiferencia, en el marco de un particular proceso local como fue el apartheid, sistema institucionalizado desde mediados del siglo XX y hasta 1994. Asimismo, resultó significativo dilucidar el entramado de mediaciones simbólicas, institucionales y jurídicas que permitieron la puesta en marcha de dinámicas de antagonismo, negociación y la alternancia entre ambos para dar cuenta de la heterogeneidad y la persistencia de articulaciones político - religiosas presentes en el devenir sudafricano contemporáneo.

Las mencionadas adscripciones fueron seleccionadas tanto por la cantidad de fieles que nucleaban como por su ascendiente sobre la población, su proyección espacial, sus acciones misionales y sus expresiones concretas derivadas del ideario de fe. Las modalidades de interrelación internas que sostuvieron dependieron de las fluctuantes circunstancias del devenir histórico, y de la diversidad de formas posibles de relacionarse, por medio de una trama de actores que, con sus acciones y omisiones, definieron hasta los más mínimos intersticios de sus relaciones sociales e institucionales. Tanto el aporte del corpus documental utilizado para el proceso de otorgar voz a los protagonistas -individuales e institucionalescomo los testimonios y relatos emanados, por medio de la historia oral en la tarea de campo, fue valioso, pues visibilizó un nutrido entramado colectivo y brindó una mirada plural a la configuración teórico / conceptual.

\section{Historia y fe}

La difusión del cristianismo protestante hacia y en el continente africano en general, y particularmente de cuatro denominaciones seleccionadas: anglicanismo, calvinismo, metodismo y pentecostalismo, fue abordada a partir de una perspectiva situacional, centrada 
en tipos y mecanismos textuales específicos, para captar el conjunto de operaciones puestas en juego, derivadas de una imagen misional general, junto con las mediaciones locales, que contribuyeron a un entramado múltiple y cambiante (ANDERSON, 2005). En tal sentido, quedaron expuestas las eventuales subversiones de las relaciones de prelación entre las iglesias como institución, sus integrantes y/o líderes, y sus objetivos. En las excepciones radicó el campo más rico de construcción discursiva, mientras que las constantes actuaron reforzando y reproduciendo estereotipos (BARUFFO, 1974).

La historia del cristianismo protestante en África fue el de las iglesias fruto de la Reforma, que se propusieron interactuar con dicha sociedad de modos diferentes. Inicialmente estuvieron poco orientadas hacia la actividad misionera concreta por principios teológicos aún en proceso de cambio y por conflictos internos / escisiones, entre otras razones. Los primeros movimientos fueron endebles, pero superadas algunas de las cuestiones individuales de las confesiones, fueron impulsadas numerosas iniciativas, de la mano de un renovado contexto histórico y social ilustrado, que dio cuenta de un sentido evangelizador activo a partir del siglo XIX. Hubo presencia de misiones interdenominacionales, como la Sociedad Misionera de Londres, a las que se sumaron juntas, como la de la iglesia anglicana (BEDIAKO, 2000). Luego surgieron las designadas misiones de fe, no dependientes de ningún cuerpo eclesiástico, y las sociedades misioneras especializadas en determinados ministerios, como el medicinal, el educacional, entre otros.

En cuanto a su potencialidad espiritual, poseían un fuerte impulso a la acción sustentado en la falta de temor por llevar 'la bandera de la religión, que los protegería de todo mal’. Su expansión estuvo principalmente motivada por el sentido de difusión de la fe, derivado de la esencia doctrinal misma a la vez que de la necesidad de asistir espiritualmente a quienes, en un momento histórico de expansión transcontinental, se hallaban residiendo o habían emigrado a otros continentes.

La recepción, en general, osciló desde la hostilidad, la sospecha, la persecución y la amenaza hasta la indiferencia, la aceptación y el logro de la expansión del evangelio. Las diferencias culturales pudieron ser superadas según la flexibilidad individual, la persistencia y la capacidad de generar vínculos con los evangelizados (HEXHAM, 1980).

. No obstante, desde que el dominio colonial europeo se impuso en el continente a finales del siglo XIX, los misioneros debieron interactuar más y con nuevas premisas con los cuadros 
administrativos, mientras penetraban hacia el interior del territorio en la búsqueda de nuevos fieles.

Ya en el siglo XX, se observó el modo en que las estrategias evangelizadoras estuvieron en todas las adscripciones dirigidas tanto a la cuestión espiritual como a la promoción humana (BHABHA, 2013). Paulatinamente, las iglesias comenzaron un proceso de africanización en tanto fueron fusionando valores cristianos con los autóctonos y se produjo el surgimiento de denominaciones locales lideradas por africanos que fueron convocantes de sus pares. Los aspectos negativos de los misioneros europeos también impulsaron a que esos emprendimientos fuesen apoyados, y los fieles buscaron dejar atrás maltratos y coerciones que en todas las adscripciones estuvieron presentes.

En tal sentido, ese proceso de transferencia de teologías de mundos culturales diferentes, con el tiempo devino en el surgimiento de nuevas formas de cristianismo dotadas de una personalidad propia a pesar de las limitaciones que su expansión en contextos coloniales pudo haber impuesto (KOSCHORKE ET AL, 2005).

Evidentemente, el arribo a regiones disímiles y con estructuras espirituales tan diferentes no hizo la tarea simple, y sobre el terreno se fueron ejerciendo, reelaborando y hasta inventando estrategias acordes a la necesidad.

El impacto en los colectivos humanos fue heterogéneo y resultó en un entramado de situaciones difícilmente catalogables: osciló desde la completa aceptación de la nueva fe hasta el extremo opuesto de irreductible resistencia (Abercrombie et al: 2003). Situaciones de fusión, reelaboración y tránsitos espirituales múltiples acompañaron a casi todas las experiencias. En las regiones donde hubo éxito, entendido éste como conversión y sostén en la práctica religiosa, lentamente se inició un cristianismo contextual que copiaba la organización impuesta. Resultó relevante comprender que, ante la mayor rigidez de la estructura colonial, las de la fe también parecieron endurecerse, y el perfil de los fieles resultaba diferenciado. En las áreas urbanas el nivel de aceptación era mayor, y la resistencia se profundizaba en la medida en que avanzaba hacia zonas interiores y/o rurales, en las que costaba más sostener presencia efectiva y permanente. 
No pueden ser establecidas generalizaciones, ya que cada comunidad estableció vínculos particulares con la adscripción que se instalara. En el caso de que hubiese varias, la admisión de una u otra muchas veces dependía de variables aleatorias, como distancia, frecuencia, contactos previos con europeos, características de la población, entre otras. Con el tiempo, la interacción se nutrió de cambios que tuvieron relación con ajustes teológico/doctrinales, modalidades de liderazgo pastoral, líneas de acción informadas desde la sede central europea, desarrollo de una liturgia propia, situaciones todas que profundizaron la flexibilidad y la contextualización con el ámbito local (COMAROFF, 1985).

En el caso sudafricano, las particularidades fueron varias: por un lado, la presencia europea fue más temprana, y caracterizada por la interacción de británicos y afrikaners, entre otros migrantes instalados. Así, la iglesia anglicana, al igual que la metodista, mantuvieron buen vínculo con la sede central, mientras continuaban con el sentido pastoral inclusivo de población multiétnica (CZEGLÉDY, 2008). Como contrapartida, en la iglesia reformada la definición identitaria de los afrikaners como el pueblo de africanos blancos elegidos por Dios para liderar las cuestiones de fe en el continente', los condujo al sesgo racista y discriminador que décadas más tarde se institucionalizaría como sistema de apartheid. La pentecostal, de ingreso posterior en la escena religiosa sumó una nueva vertiente a la pluralidad que, junto con las ya mencionadas, condujo al complejo proceso de difusión del cristianismo a todas las comunidades africanas. Éstas devinieron en numerosos núcleos de recepción de fieles que, con el tiempo, asistieron a escisiones y cambios que dieron lugar a congregaciones independientes, en las que el componente étnico fue una variable decisiva.

En definitiva, el panorama de la expansión misionera cristiana en el continente africano, particularizado en las regiones al sur del Sahara, tuvo importancia tanto por la territorialidad que abarcó como por la diversidad de denominaciones que encabezó. En ese contexto, coexistieron las corrientes europeas y las locales surgidas como derivaciones de gran heterogeneidad. Las religiones preexistentes en aquel escenario, por su parte, atravesaron por serios desafíos ante la imposición del dominio colonial y el advenimiento de las mencionadas misiones, que fueron considerados como cambios de paradigma derivados del momento histórico, tanto en el contexto local como en el de las propias adscripciones (WALSHE, 1987).

La cosmovisión distorsionada y paternalista de la que fueron objeto, motivó la resistencia por múltiples causas, entre las que se hallaba la dicotomía teológica entre lo \begin{tabular}{l|l} 
Revista RBBA & Revista Binacional Brasil Argentina
\end{tabular} 
sagrado y lo secular en las iglesias, y la prédica de un evangelio individualista que fomentaba la idea de una transformación personal sin considerar lo colectivo (Agamben: 1978). No obstante, se detectó que tales religiones, presentes desde el pasado en la escena sudafricana, pervivieron resignificadas en el conjunto de retóricas teológicas utilizadas por los misioneros. Los mecanismos de fusión, adaptación y reelaboración operaron produciendo en ellas superposiciones y fusiones (GLUCKMAN, 1991).

A su vez, el cristianismo protestante, lentamente se convirtió en una vigorosa influencia en África en general y en Sudáfrica en particular, uniendo grandes cantidades de personas en una fe común que se expresaba y materializaba a través de disímiles modalidades de pensamiento y acción. Tales diferencias se profundizaron con el paso del tiempo, y produjeron múltiples escenarios teológico - misionales. Cada región, adscripción, momento histórico e identificación con personalismos pastorales condujo a una intensa diversificación tanto de formas de profesar la fe como de contenidos.

Las disidencias teológicas locales surgidas entre el siglo XVII y XIX generalmente estuvieron sustentadas tanto por la discrepancia teórica con las sedes europeas, agudizadas por la distancia, como por las disputas locales en torno de quiénes, cómo, de qué modo y dónde debían ser objeto de la incorporación al culto (Westhuizen: 1991). Durante el siglo XX, todos esos tópicos se profundizaron ante el avance de la implementación de las divisiones raciales a través de la filosofía política e ingeniería social del apartheid, y fue la iglesia reformada holandesa la que principalmente operó, en una pragmática fusión, con el poder político.

La anglicana y la metodista, por su parte, sostuvieron adaptativas y fluctuantes acciones, actuando diferenciadamente en los niveles de jerarquía y congregacional. La pentecostal tendió, desde su expansión, a eludir conflictos con el poder político, llegando en la mayoría de los casos a situaciones de sometimiento al sistema vigente. Así, las cuatro expresaron en sus niveles internos, a lo largo del tiempo y en escenarios heterogéneos posicionamientos que derivaban de la estructura teológica a la cual pertenecían. No obstante, y a pesar de la rigidez de la estructura legal de la etnocracia vigente, evidenciaron disidencias y tomas de decisiones que demostraron que no fueron espacios homogéneos ni estáticos, sino fluidos y signados por contantes intercambios. 


\section{Ideas y acciones}

El análisis de las vinculaciones entre el poder, en su expresión política, y cuatro adscripciones cristianas protestantes seleccionadas en Sudáfrica, desde mediados del siglo XX hasta el presente permitió dar cuenta del impacto ocasionado en el escenario tratado. Del mismo modo, se pudo comprender el modo a través del cual el sector gubernamental construyó un andamiaje de segregación apoyado tanto en una profusa normativización legal como en una fundamentación teológica que posicionaba a la población blanca como superior.

Así, el cristianismo protestante devino en una poderosa influencia ideológica, pues si bien partía de un núcleo bíblico común, adoptó enunciados diferenciados. Las iglesias propusieron una respuesta cristiana a situaciones locales, y para ello se expresaron de modo diverso, acorde con disímiles interpretaciones contextuales. Concretamente, en el sentido amplio de su cosmovisión, aquél fue propulsor de ideas de igualdad e inclusión para la minoría blanca en el ejercicio del poder político (Balcolm: 2004). A su vez, constituyó la base ideológica utilizada por el gobierno para justificar la política de desarrollo separado para la población no blanca, que sumó a la opresión institucional y étnica, la de la fe, fundamentada incluso bíblicamente.

Tanto en lo político como en lo religioso hubo multiplicidad de entrecruzamientos ideológicos, y los actores individuales / colectivos, en ámbitos de liderazgo / en las bases, no siempre respondieron al sector religioso, político, étnico, social o ideológico al cual pertenecían. Así como no toda la población blanca sustentó el apartheid, tampoco las adscripciones religiosas sostuvieron una respuesta homogénea a sus imposiciones, hecho que generó un escenario diverso, cambiante y flexible de enfoques y acciones fluctuantes en el tiempo (ELÍAS, 1983).

La interpretación discursiva y de las prácticas ejercidas tanto por representantes políticos como religiosos, que de modo personal/institucional pusieron en juego mecanismos de articulación tendientes a interactuar en el marco situacional seleccionado, denota la fuerte racialización que operó en todo momento como sustrato del apartheid, y los elementos emanados de las iglesias y/o de sus teologías cristianas protestantes ofrecieron en Sudáfrica, desde el siglo XX, una plataforma ideológica para el sostén de un marco religioso en el cual se apoyó aquel sistema de segregación. Del mismo modo, otros aspectos de aquéllas 
constituyeron una fuerza potenciadora de la resistencia que lideró acciones para el logro de la liberación de dicha práctica (BOESAK, 2014). Reformados, anglicanos, metodistas y pentecostales, expresaron en sus diferentes niveles, a lo largo del tiempo y en escenarios heterogéneos posicionamientos que en muchos casos iban más allá de la estructura teológica a la cual pertenecían, evidenciando tomas de decisiones que los situaron en espacios heterogéneos y dinámicos.

La Iglesia Reformada Holandesa o Nederduitse Gereformeerde Kerk, concretamente, promovió las divisiones raciales y la segregación espacial, considerándolas beneficiosas para la protección de los nativos ante el contacto con una cultura como la europea que podría ser disruptiva por ser superior. La doctrina de aquélla emanaba de las tres declaraciones de fe reformadas: el Catecismo de Heidelberg, la Confessio Belgica y los Cánones de Dordt. En este último documento, en particular, se resaltaba la idea calvinista que sostenía que Dios había predestinado a aquellos que él quería salvar. El corte de vínculo con las iglesias madre desde el siglo XIX les produjo un sentimiento de vacío cultural que exacerbó su percepción de superioridad, por lo cual el aislamiento fue considerado necesario para la supervivencia. En el mismo sentido, resulta relevante afirmar que fue decisivo el estímulo que se dio a los fieles para la actuación en la política de gobierno, afirmación en la cual se apoyó al sistema de apartheid.

Hubo escisiones hacia su interior por cuestiones de liderazgo y diferencias teológicas, de las cuales surgieron la Nederduitsch Hervormde Kerk y la Gereformeerde Kerk van Suid Afrika. No obstante, las tres compartieron la estructura doctrinal básica: 'Dios es eterno, infinito, sabio, justo y el creador del universo; ha planeado la vida y el destino de cada individuo en la tierra; y los elegidos se salvarán si adhieren a las enseñanzas de la Biblia, de la que emana la autoridad conceptual’ (PROZESKY et al, 1997).

Luego de la finalización del apartheid, la iglesia en su conjunto pidió disculpas por la posición que había adoptado históricamente, reconociendo que las expresiones de apoyo a aquél, emanadas del texto bíblico, no correspondían como legitimación de un orden político como el que había sido impuesto (HORREL et al, 1975). 
Los anglicanos, por su parte, según su ideario pragmático habían sostenido su presencia en Sudáfrica desde el siglo XIX en fluido contacto con su metrópolis, desde donde se impulsó la expansión misional entre los pueblos a los que 'Dios no había llegado'. A lo largo del tiempo, sus iglesias esgrimieron un liderazgo en el que se resaltaba la superioridad moral en relación con otras adscripciones, y sobre todo con la reformada. En la Comisión para la Verdad y la Reconciliación, se presentaron para pedir perdón a los feligreses negros por no haber tomado más acciones concretas para desafiar las políticas discriminatorias del gobierno blanco, con las cuales fueron complacientes: 'We are here to say to God, and the world, that we have fallen short of your glory'. Así, la iglesia reconoció como institución que había sostenido un 'letargo moral' por medio del cual había desarrollado un patrón de desigualdad racial y de discriminación contrarios a sus principios esenciales. Algunos de sus líderes se pronunciaron en oposición al apartheid, pero los miembros en general soslayaron las decisiones mientras disentían en la forma de expresar sus puntos de vista (WILSON, 2000).

La iglesia metodista, independiente de su institucionalidad británica desde 1882, comenzó a desarrollar tempranamente instancias de liderazgo negro a la vez que sostenía cierta oposición a medida que el apartheid endurecía su represión como consecuencia del incremento de la resistencia general en el país. En tal sentido, su sentido ecuménico fue ambiguamente desafiante de las medidas que el gobierno racista imponía.Si bien tuvo una importante cantidad de fieles negros, que expresaron su oposición al apartheid, predominó el sostén de posiciones de formal apoyo al gobierno blanco entre sus líderes, en una fluctuante y polémica superposición (MANA, 1992).

Desde la instauración de la democracia, la iglesia expresó que 'pudo retomar el camino que, interrumpido por las oscuras décadas, no había podido ser cumplido acorde a la misión divina'. De ese modo, propusieron que la iglesia debía realizar una renovación de la esperanza cristiana, para que la transformación en la vida de los sudafricanos permitiera el diálogo y la convivencia, como si fuese 'viaje a una nueva tierra' (DE GRUCHY VILLAVICENCIO, 1993).

Los pentecostales, ingresados en el territorio desde 1908, lograron en menos de un siglo, extender su mensaje a un alto porcentaje de la población. El conjunto de sus iglesias incluyó a varias denominaciones, a iglesias afiliadas y otras independientes que, junto con múltiples organizaciones más pequeñas formaban grupos socialmente significativos tanto en el ámbito rural como en el urbano. Todas evitaron enfrentar abiertamente la estructura política

\begin{tabular}{l|l} 
Revista RBBA & Revista Binacional Brasil Argentina
\end{tabular} 
opresora, y, a veces inclusive la apoyaron, a pesar de sus afirmaciones de igualdad de la humanidad ante los ojos de Dios'. Muchas sostuvieron que 'la participación en política era un pecado', y que 'Jesús los liberaría por medio del evangelio'. Mientras tanto, debían apoyar al nacionalismo blanco y su apartheid para mantener el orden vigente. Luego de instaurada la democracia plena, argumentaron, en relación con el pasado opresor que habían sido engañados por el gobierno del Partido Nacional hasta que percibieron que aquél imponía un sistema cruel al que no habían cuestionado, reconociendo que su error fue por su posición apolítica, y que por ello no habían comprendido el sufrimiento de la población negra (DU TOIT, 1983).

En la etapa postapartheid, desde 1994, las iglesias tuvieron, en general, tanto en su naturaleza como en su contenido, intervenciones políticas diferentes: algunas se expresaron opositoras al cambio y promovieron la preservación de modalidades preexistentes; otras sostuvieron indiferencia, y un tercer grupo, propugnó por la participación activa, incluyendo la participación política y hasta la formación de un partido (BORAINE, 2014). Así, luego de la anterior descripción se sostiene que la etapa democrática halló rápidamente justificaciones teológicas e ideológicas para rediseñar el pasado. Los reclamos, los silencios y las acusaciones fueron en algunos casos olvidados y, en otros, mitigados para dar paso a nuevas realidades (VERWOERD, 1999).

En síntesis, en perspectiva histórica, las adscripciones religiosas, luego de desplegar sus doctrinas y prácticas, de fuerte contenido ideológico, devinieron en portadoras de constantes mensajes de gran influencia sobre el gobierno. La interpretación religiosa que realizaron de aquél, así como de la autoridad política, del estado y su organización, estuvo enmarcada predominantemente en una lectura politizante. Como contrapartida, el poder político, en tanto poseedor del control y la decisión, construyó fundamentaciones religionalizantes de sus principios y acciones, de modo tal que el orden institucional impuesto parecía emanar de los designios de Dios en un relato que narraba el pasado y dirigía el presente (PLAATJIES VAN HUFFELL et al, 2013). En este sentido, sus relaciones con el ámbito religioso operaron como catalizadores de reacciones y resistencias. 
Los sudafricanos, por su parte, adhirieron mayoritariamente al cristianismo protestante luego de un lento proceso de fusión con los elementos principales de la cosmovisión local. De ese modo, dicha confesión constituyó la base ideológica a partir de la cual se pudo pronunciar la resistencia a la opresión etno / institucional para el logro de la liberación y la equidad (PROZESKY et al, 1997). Las ideas, como las de la teología de la liberación, entre otras, lograron expresar elementos de interpretación de la realidad basados en los fundamentos de la doctrina cristiana, que vehiculizaron un marco apto para la percepción política y sobre todo, social. No obstante, siempre hubo fracturas internas, divergencias de intereses y de posiciones e inversiones de jerarquías llevadas a cabo de la mano de negociaciones.

De ese modo, fue sostenido en el tiempo un equilibrio que sustentó la continuidad del sistema de explotación que implicaba el apartheid, en el que se producían intensos y numerosos intercambios entre los actores institucionales e individuales de ambos sectores opresores y oprimidos-, motivando que la separación, el conflicto y la cooperación se combinaran y resignificaran permanentemente (TUTU, 2012). Cuando la lucha de fuerzas de aquéllos estuvo estancada y ninguno pudo avanzar sobre el otro, el escenario sólo pudo posibilitar una transición pactada, en la cual los blancos cedieron el poder político a cambio de mantener la mayor parte del control del orden económico, junto con cierta garantía de un tratamiento benévolo en relación las acciones llevadas a cabo en el pasado (ARDUINO, 2014).

Luego se impuso la necesidad de una metamorfosis social, política y económica, en la cual una Comisión para la Verdad y la Reconciliación, colaboradora con la pacificación, impulsó, junto con el poder político, las mediaciones simbólicas, jurídicas e institucionales que permitieron la puesta en marcha de dinámicas de reconciliación social (WIREDY, 1988). Por todo lo antedicho, los imaginarios ideológicos - religioso e ideológico - político actuaron durante la transición hacia la democracia, como operadores de la transformación, de la reconstrucción de la memoria histórica en sus formas oficiales y no oficiales, y de la restauración de los vínculos entre lo personal y lo social para articular luchas pasadas con reivindicaciones presentes y proyecciones futuras.

En tal sentido, así como la interpretación bíblica resultó relevante por haber constituido la base ideológica tanto de los opresores como de los oprimidos, luego de finalizado el apartheid e iniciado el proceso de restauración sociopolítica que permitió la gradual conformación de una sociedad democrática y plural, surgieron renovadas diferencias

\begin{tabular}{l|l} 
Revista RBBA & Revista Binacional Brasil Argentina
\end{tabular} 
discursivas entre las denominaciones protestantes, algunas más bien parecidas a justificaciones del pasado y otras, como vehementes aportes tendientes a la cohesión social. El poder político, por su parte, a partir de 1994 redimensionó su posición frente a dichas iglesias, a través de un mensaje inclusivo y reconciliador, en un intento de superación de las adversas situaciones vividas. Un nuevo texto constitucional aprobado en 1996 y vigente desde 1999 incluyó protecciones para todos los grupos culturales, lingüísticos y religiosos, con el fin de respetar a todas las identidades.

Luego de una mirada en perspectiva histórica, es importante aseverar que tanto las iglesias cristianas protestantes como el gobierno sudafricano mantuvieron, en cada etapa y hasta el presente, heterogéneas, oscilantes y hasta contradictorias vinculaciones que expresaron instancias de oposición, neutralidad y negociación alternativamente y/o en simultaneidad. Más allá de las pertenencias étnicas, ideológicas, religiosas, institucionales, fueron promovidos acuerdos y disidencias que se evidenciaron en las diferentes circunstancias del recorrido histórico investigado. Resulta relevante, entonces, la confirmación de la persistencia y los matices de tales interacciones entre los actores investigados, en contraste con la imagen que surge de la bibliografía, generalizadora de la escasez vincular entre aquéllos.

Concomitantemente, hubo constante intercambio ideológico que las iglesias protestantes sostuvieron con la esfera del poder político, hecho que da cuenta de las fluidas interacciones entre los protagonistas, tanto políticos como religiosos, institucionales e individuales, en un rígido espacio como el de la etnocracia sudafricana. Así, la agencia política, tanto de las iglesias como del gobierno, generó un escenario basado en el interjuego de estrategias por medio de las cuales fue sostenida la mutua interacción, la pragmática convivencia, el conflicto y las transacciones. Todas esas relaciones se caracterizaron por su caleidoscópica y basculante modalidad. El final del apartheid, que para muchos constituyó un 'milagro', en definitiva fue más bien una supervivencia: la necesidad de continuar con la existencia y con nuevos desafíos. Si bien hubo muchas buenas intenciones, la realidad es que Sudáfrica aún posee huellas muy visibles de las consecuencias de su pasado, que aún no ha logrado superar. 


\section{Política y religión entrecruzados}

El análisis de los diferentes momentos teológicos permitió apreciar el marco ideológico de su relación dialéctica con el poder político, tanto para la toma de conciencia y la resistencia como para la justificación y la persecución relacionada con el apartheid. Los temas centrales tratados en ellos fueron diversos, y oscilaron entre el deterioro socioeconómico, la explotación neocolonial y la racialización segregada de la sociedad. La búsqueda de solución para tales situaciones propulsó la implementación de una teología liberadora, como la negra, que se presentó como una reacción crítica al racismo y a la segregación, considerados como fenómenos ligados al capitalismo y la explotación.

Aquélla propició que se volviera a ser expresión de humanidad y del proyecto originario de Dios'. De ahí que algunos autores hayan hablado de ella como contextual, porque expresaba mejor su esencia en el marco histórico en el que se hallaba, por ejemplo, el pueblo sudafricano, históricamente sometido a la opresión.

Para descolonizar a la teología del influjo occidental y provocar una ruptura epistemológica con las de otros países, la desarrollada en África propuso establecer reflexiones y praxis más realistas y significativas, tendientes a no romper la relación entre la fe y la vida real del pueblo africano oprimido, pero sí a lograr la liberación por medio del anuncio y la práctica de un evangelio de carácter antiopresivo. Tales principios, en general, provinieron de la Biblia, la fuente tradicional, ya que, ante todo, los teólogos africanos mantuvieron su particular interpretación por la que se vinculaba la unidad eclesial en la diversidad cultural, en la que estuvieron históricamente situados.

Mientras tanto, a pesar de la segregación blanca, la compleja realidad sudafricana profundizaba, sin poder evitarlo, los cruces, las interrelaciones y las rupturas que interconectaban los diferentes elementos que operaban en la experiencia colectiva de sus espacios y actores. De ese modo, la dinámica de las relaciones interétnicas implicó un tipo de interacción en la que necesariamente debieron existir intercambios para el sostén de cierto equilibrio en el que operó la alternancia de conflicto, cooperación y negociación, aunque tales mecanismos no dejaron de estar condicionados por el modelo de dominación vigente. En ese

\begin{tabular}{l|l} 
Revista RBBA & Revista Binacional Brasil Argentina
\end{tabular} 
marco, la política y su vínculo con los actores sociales tanto impulsores de ella como los receptores, resultaba ser el proceso de instrumentación de las metas de la minoría blanca en el gobierno a través del uso diferenciado del poder sobre la mayoría oprimida. De ese modo, se sostuvo un equilibrio que permitía la continuidad del sistema de explotación en el que habría intercambios estratégicos entre los grupos.

En el escenario teológico, el rasgo predominante fue el de la multiplicidad de situaciones que derivaban del interjuego de actores, espacio físico -urbano / rural / periurbano-, pertenencia étnica, ocupación, adscripción religiosa, nivel de instrucción, entre otras, a las que se sumaba el perfil pastoral de quien estuviese a cargo, su rango en la estructura de la iglesia, y su manejo o no de fondos derivados de la jerarquía denominacional. Las tendencias ideológicas, interpeladas con acercamientos cuantitativos, indicaron que, si bien la iglesia reformada sostuvo en el tiempo una constante cercanía al poder político del apartheid, constituía una minoría comparada con adscripciones numerosas como la pentecostal, que se mantuvo presuntamente neutral hasta 1994. Por su parte, pastores como los metodistas y los anglicanos, en contacto directo con los fieles, pudieron sostener y hasta favorecer estrategias adaptativas y flexibles que constituyeron intersticios a través de los cuales se efectuaba la descompresión derivada de las tensiones acumuladas por la opresión.

Las acciones fueron heterogéneas, y podían expresarse desde el permiso para dialogar luego del servicio religioso o fúnebre sobre cuestiones extra - devocionales, hasta los casos de pastores blancos que abandonaron su iglesia segregada y se incorporaron a otra para población negra y coloured. Un punto que se resalta es el de la fundamentación bíblica. En tal sentido, las adscripciones buscaron, a lo largo de la existencia del sistema etnocrático, reinterpretar las Escrituras en la búsqueda de fundamentaciones para instancias vigentes en la realidad, pero no les resultó fácil expresar conceptos de igualdad ante Dios, hermandad, etc. acordes a la situación institucional en curso.

La iglesia reformada, en cambio, y tal como fue expuesto, basó su corpus teológico en el sentido misional de conformar el pueblo elegido al que 'Dios le había encomendado la tarea de llevar a África la fe que pueblos, paganos e inferiores', debían aprender sin ser influenciados culturalmente, para lo cual se debería implementar el desarrollo separado. Los 
metodistas, promotores históricos de la lucha contra toda forma de explotación, extrapolaron la experiencia inicial obtenida en las colonias americanas, buscando promover tales ideas, pero, al igual que los anglicanos, no siempre lograban que sus superiores les otorgaran anuencia para sostenerlas según la demanda del contexto local. Los pentecostales, por su parte, comenzaron a profundizar e incrementar su actuación casi junto con el momento del desmantelamiento del apartheid, y procedieron a favor de los fieles en instancias de bajo impacto, como el otorgamiento de contención emocional, refugio temporal o asistencia espiritual, evitando incurrir en enfrentamientos directos con el poder político.

Todos los anteriores, en el aspecto teológico utilizaban un lenguaje análogo en lo conceptual -Dios es justo, onmipotente, sábio - y metafórico, con el empleo de imágenes y símbolos -Dios es el guía, el sanador -, apelando en todo momento a la capacidad evocadora para la asimilación de experiencias y la conexión pasado - presente. También, en el conjunto de una cristología multiforme, se veía potenciada la capacidad activadora hacia la acción, empleada tanto para la sumisión -Dios así lo ordena- como para la resistencia-Dios quiere para ti la felicidad-. En las alocuciones, se pasaba por momentos de mediación analítica o de interpretación, luego hermenéutica o de juicio y finalmente de práctica o movilización.

Para todas, la 'experiencia bíblica fundamental era el Éxodo, en el que Dios liberaba a sus hijos de la opresión, de la distribución injusta de la riqueza, de la violencia, de la pobreza'. Mientras para un reformado tales atributos le correspondían sólo a los blancos y en el presente, como compensación divina por pesares vividos en el pasado, para los oprimidos no blancos, tales afirmaciones solamente constituían esperanzas a futuro. La contradicción también surgía cuando, ante las acciones llevadas a cabo como forma de resistencia se producían actos de violencia. En ese sentido, quienes desde lo teológico las habían incentivado como lucha antiapartheid, debían recurrir a argumentos tomados de situaciones épicas que los justificaran.

En definitiva, todas las iglesias buscaron la fundamentación de las acciones presentes, individuales y / o colectivas, por medio de una reinterpretación bíblica justificadora, explicativa o movilizadora hacia la acción, según la circunstancia. En esos ajustes dialécticos hubo instancias dramáticas que afectaron tanto a las propias adscripciones, que luego de 1994 debieron disculparse públicamente, como a los fieles.

Aquéllas, además, sostuvieron contantes relaciones con el poder político, diferenciándose en la modalidad y en el nivel de conflicto producido: mientras la reformada 
apoyaba todo el andamiaje legal que se emitía desde el gobierno, la anglicana optaba por el envío de documentos escritos con puntos de vista disidentes basados siempre en miradas teológicas. En tal sentido, el apartheid, parecía emanar fantasmagóricamente de las Escrituras, conduciendo a unos hacia un destino prometido, mientras que a otros les otorgaba, o bien la esperanza de que algún día lograrían justicia y equidad, o bien el acicate para la acción antiopresiva. Entre esos escenarios, millones de personas quedaron, simbólicamente, atrapadas entre el bien que luchaba contra el mal, y el campo de batalla era su sufrida cotidianidad.

Luego de los años finales de violencia y represión, el régimen tuvo que comenzar a dialogar con la oposición, en una miríada de negociaciones que, junto con un zeitgeist condujo a la redimensión tanto del poder instrumental y represivo del gobierno blanco como de la forma de ser cristiano, y sus mutuas interconexiones. La población blanca, por su parte, tampoco tuvo opinión y participación homogénea. Conscientes de la exacerbación segregacionista, no siempre pudieron reaccionar ante el temor de ser criminalizados por complicidades o delitos de asociación. No obstante, hubo detractores del apartheid que participaron de diferentes modos en su contra, por ejemplo, en periodismo.

Desde los años '90, reuniones y documentos públicos, oficiales y religiosos expresaron la necesidad urgente de la pacificación, responsabilizando al estado y a los partidos políticos tanto por las acciones como por omisiones de sus funcionarios o miembros. Para iniciar la transición hacia la democracia plena, fueron puestos en funcionamiento recursos como el del funcionamiento de una Comisión de la Verdad y la Reconciliación, la aprobación de un texto constitucional en 1996, garante de la democracia multipartidaria y multirracial, y múltiples reuniones institucionales tendientes al sinceramiento, pues aún quedaban tensiones pendientes del pasado.

Aquél fue reinterpretado a partir de una plataforma narrativa basada en un idealismo moral y en la teología cristiana. Para ello fueron utilizadas metáforas como la que relacionaba a las heridas de los cuerpos de las víctimas con las que había sufrido la nación como un todo, en un intento de articular lo individual con lo colectivo. La necesidad de reestructuración social llevó, como ideal de transformación a la búsqueda de erradicación de las circunstancias 
que habían contribuido a una prolongada desigualdad. Para ello sería necesaria la implementación de programas de compensación y de empoderamiento sostenidos en el tiempo.

No resulta difícil imaginar la complejidad de tal proceso, cuando las fuerzas sociales que habían liderado la opresión aún estaban presentes en parte de las instituciones. Igualmente, la desegregación avanzó en todos los órdenes, aunque actuó como un nuevo mecanismo que llevó al surgimiento de lógicas de clase en reemplazo de las de etnicidad. Las iglesias, entonces, se expresaron nuevamente a través del escenario bíblico, resaltando las bondades de la construcción de una nueva sociedad basada en la justicia, para colaborar con la sanación del pasado. Señalaron los valores a seguir, como la educación, para que la nueva sociedad civil, en un orden socioeconómicamente equitativo permitiera la mejora de la calidad de vida y el empoderamiento de los otrora oprimidos. Para ello, el principio moral de ubuntu debía convertirse en acción.

Mientras se diluía la expectativa de fuertes conflictos interétnicos para la etapa democrática, muchos sudafricanos reinterpretaron la realidad, que había sido atribuida al 'milagro' reconciliador de los años noventa. Comprobaron que más bien se trató de cuestiones de supervivencia, y que la sociedad necesitaba continuar con su devenir y con nuevos desafíos. En ese nuevo contexto, las iglesias cristianas, junto con sus doctrinas y prácticas, continuaron en estrecha relación con el poder político, a la vez que éste solicitó recurrentemente la colaboración de aquéllas para la reconstrucción social postapartheid, el sostenimiento de instancias de pacificación y la reelaboración de una memoria colectiva superadora de los traumas del pasado.

De ese modo, un sector de la teología cristiana protestante ofreció en Sudáfrica, desde mediados del siglo XX y hasta el presente, tanto una plataforma ideológica para el sostén de un marco religioso en el cual se apoyó el apartheid, como las argumentaciones y el impulso potenciador para acciones de resistencia, tendientes al logro de la liberación de dicho régimen. Luego del recorrido realizado a través de las relaciones entre la política y la religión, aún quedan cuestiones por resolver, como el vínculo que se establece en el presente con una 'sociedad reconciliada', los reproches por el pasado, lo incumplido en la nueva etapa, y la planificación a corto y mediano plazo.

La búsqueda de espacios de interrelación entre ambos constituyó un desafío complejo a la vez que cambiante, dado que las dos dimensiones son relevantes en dicho país, y que han

\begin{tabular}{l|l} 
Revista RBBA & Revista Binacional Brasil Argentina
\end{tabular} 
tenido, en su perspectiva histórica, múltiples encuentros y desencuentros en el marco de mutua autonomía a la vez que recíproca interdependencia. La religionalización de la política no constituye un fenómeno nuevo en la historia, pero sí lo es el marco en el cual se manifiesta. En Sudáfrica, los aspectos religiosos no solamente se yuxtapusieron con aquélla, a modo de verdad reforzada, sino que condicionaron y desplegaron nuevos sentidos de realidad hacia una deriva utilitaria que demarcó ideas y escenarios legitimados por dogmáticas construcciones de manipulación.

Todos los aspectos de la existencia de la población fueron alcanzados por las normativas emanadas de aquel régimen racialista, alienante y segregador, a través de una retórica religionalizante: 'Dios así lo quiso', 'si Dios hubiese querido que fuésemos iguales así nos hubiese hecho', etc. Así, se consolidó un andamiaje de mensajes que dicotomizaron la realidad entre el blanco y el no blanco, que sólo era funcional para ser trabajador explotado y servidor obediente.

La politización de la religión, por su parte, también instalada desde el pasado en los avatares históricos, adoptó en el siglo XXI una nueva dimensión. A medida que la religión ocupó un espacio cada vez más importante en la política y la vida pública, su politización se sumó a los desafíos de la gobernabilidad, ya que pudo actuar como fuerza divisoria en el ámbito social e ideológico.

Además, la elección de aliados políticos permitió a una religión defender mejor sus intereses, tanto para ganar una posición privilegiada y un trato preferencial ante el gobierno, como por una cuestión de recursos. La tendencia polifacética de la politización de la religión, suele relacionarse en el caso sudafricano con la búsqueda de liderazgo acorde a principios etnoculturales de superioridad de grupo que pretendieron sostener tanto los políticos como los religiosos reformados en desmedro de los no blancos y de otras adscripciones.

Las adscripciones religiosas seleccionadas, junto con sus doctrinas y prácticas, han dado cuenta de un fuerte contenido ideológico, portador de constantes mensajes que impactaron en la esfera del poder. A su vez, la interpretación religiosa que realizaron de ese poder, así como de la autoridad política, del estado y su organización, siempre estuvo enmarcada en una lectura religionalizante de aquél. El poder político, por su parte, cooptador 
por naturaleza intrínseca del control y la decisión, construyó fundamentaciones instrumentalizantes del espectro religioso, y las manipuló en universos colectivos e individuales, en un proceso de ingeniería social cuyos engranajes tuvieron existencia $-o$ les fue quitada- en función un designio supremo.

El heterogéneo entramado de tales interacciones se combinó con las múltiples variables emanadas de los propios actores sociales, sus acciones, reacciones y omisiones, dinamizados por cambiantes escenarios temporales y espaciales. A su vez, el sustento legal, delineó la rigidez de un esquema que, como la etnocracia sudafricana, dejaba mínimos intersticios para la elusión. A pesar de ello, los imaginarios ideológico - religioso e ideológico - político fueron catalizadores de la transformación postapartheid, de la construcción de la memoria histórica en sus formas oficiales y no oficiales, y de los vínculos entre lo personal y lo social para la resignificación de una identidad sociopolítica que amoldó y modificó luchas pasadas para articularlas con reivindicaciones presentes y futuras.

Así, la 'visión de Dios', una vez más actuó como reguladora del pensamiento y de la acción, y la idea religiosa fue expresada en un lenguaje institucionalizado por el poder a toda la sociedad. Ésta recibió, de ese modo, la fusión de lo humano y de lo divino, del poder y de la religión, en un relato que narraba el pasado, controlaba el presente y aseguraba el futuro. Ese proceso de religionalización de la política, y su contracara, la politización de la religión, constituyó, en el caso sudafricano, un tránsito desde la violencia e inequidad vividas en el pasado hacia la redimensión de la realidad social presente. Hace poco más de dos décadas que dicho recorrido comenzó, y junto con la conformación de un escenario sociopolítico renovado, se busca aún la integración y la equidad para todos los sudafricanos.

\section{Consideraciones finales}

Luego del curso de la investigación, puede ser sustentado un conjunto de afirmaciones: inicialmente, queda superada la imagen emergente de bibliografía que se refería a actores sociales que supuestamente se habían desempeñado con agencias sectoriales o individuales, y limitados a sus ámbitos de actuación pública / privada, pues la dinámica de las relaciones blancos / no blancos implicó un tipo de interacción en la que hubo constante intercambio entre los unos y los otros, a pesar de las imposiciones legales que lo impedían.

Luego, y a partir de los documentos indagados, pudo ser demostrada la existencia de matices, tanto individuales como colectivos, que han sido de gran importancia. Existieron 
recurrentes divergencias de intereses y de posturas entre los individuos y los grupos, en los liderazgos y en sus bases, en la toma de decisiones, en las negociaciones y / o en los conflictos, en un momento determinado o a lo largo del tiempo. Así, el análisis de la experiencia colectiva en la sociedad sudafricana durante y después del apartheid evidencia que, como proceso complejo, contuvo cruces, relaciones y rupturas que interconectaron a los actores más allá de sus pertenencias étnicas, institucionales, ideológicas, religiosas y/o políticas, expresados por medio de la negociación, la cooperación, las disidencias y los acuerdos.

En cuanto a la descripción de las vertientes religiosas quedó evidenciado el fuerte contenido ideológico en las iglesias protestantes investigadas, portador de constantes mensajes que impactaron en la esfera del poder. Éste, por su parte, también accionó con / contra aquéllas con concretos y diferenciados postulados y acciones. En tal sentido, las imbricaciones entre los actores, tanto políticos como religiosos, institucionales e individuales, a lo largo del tiempo, fueron constantes. La modalidad de vínculo dependió del momento y la circunstancia, pero en una mutua interdependencia expresaron todas las formas posibles de articulación: la connivencia, la oposición, la indiferencia, la presión, la destrucción, la negociación, el acuerdo, la neutralidad, la traición, la reversión de alianzas, entre otros posibles.

La caleidoscópica red de tales interacciones se combinó con las múltiples variables emanadas de los propios actores sociales, de sus acciones, sus reacciones y sus omisiones, dinamizados por cambiantes escenarios temporales y espaciales, a pesar de que el arropamiento legal de la rígida etnocracia sudafricana dejaba pocos intersticios para ello. En el caso del Cristianismo Protestante, la expansión a regiones que ya tenían otras religiones, como África del sur, produjo una reconceptualización derivada del trasplante, derivando en una identidad distintiva marcada por una representación colectiva que cimentó la superioridad blanca institucionalizada como una derivación de la 'obra divina para con el otro no cristiano e inferior'. No obstante, las diferentes adscripciones se diversificaron y protagonizaron escisiones y cambios constantes. 
El apartheid, por su parte, como sistema de segregación sociopolítico institucionalizado, amparado ideológicamente en la noción de racialidad, atravesó el perfil teológico de todas las iglesias, generando variados posicionamientos adaptativos, resistentes o elusivos. Casi nunca hubo un punto de vista que nucleara argumentos expresados desde lo religioso y / o desde lo político de modo uniforme e invariable. Por el contrario, la plataforma proselitista cristiana protestante se vinculó hábilmente con el poder político a lo largo del tiempo, de modo versátil y funcional.

A su vez, los actores sociales / políticos y las formas de participación / resistencia, tanto en lo individual como en lo colectivo fueron decisivas para comprender la praxis relacionada con las mediaciones y las expresiones que entre los sudafricanos devino en cultura política, a modo de orientaciones recíprocas que no sólo articulaban a los componentes, sino que actuaban en formas diferentes y cambiantes en los diferentes niveles de organización. En ese sentido, la investigación aporta la descripción de modalidades de acción y negociación por medio de las cuales las iglesias interactuaron con el poder político, a lo largo del siglo XX y hasta el presente, tanto para validarlo como para sostener acciones de disidencia, oposición, indiferencia y/o vínculos pendulares.

\section{Referencias}

ABERCROMBIE, N.; HILL, S.; TURNER, B. Determinación e indeterminación en la teoría de la ideología. Žižek, Slavoj (Comp.) Ideología. Un mapa de la cuestión. Buenos Aires: Fondo de Cultura Económica, 2003.

ADORNO, Theodor. Mensajes en una botella. Žižek, Slavoj. (Comp.) Ideología. Un mapa de la cuestión. Buenos Aires: Fondo de Cultura Económica, 2003.

AMIN, Samir. The Issue of Democracy in the Third World. En: Academic Freedom in Africa. Senegal: Codesria, 1994.

ANDERSON, Allan. New African initiated Pentecostalism and Charismatics in South Africa. Journal of Religion in Africa. Brill. Vol. 35, 2005, Fasc. 1, pp. 66 - 92.

APPADURAI, Arjun. El rechazo de las minorías. Ensayo sobre la geografía de la furia. Barcelona: Tusquets, 2007.

APPIAH, Kwame Anthony. Cosmopolitismo. La ética en un mundo de extraños. Buenos Aires: Katz., 2007.

ARDUINO, Eugenia. Translocalización religiosa y espiritualidad resignificada. Fe pentecostal en Nigeria contemporánea. Berlín: Editorial Académica Española, 2017. 
Identidades afroasiáticas translocalizadas. Intercambios y resignificación sociocultural. Buenos Aires: Mnemosyne, 2014.

Mundos de fe. Espacios resignificados de espiritualidad en Sudáfrica contemporánea. Buenos Aires: Mnemosyne, 2014.

BALANDIER, G. El desorden. La teoría del caos y las ciencias sociales. Elogio de la fecundidad del movimiento. Barcelona: Gedisa, 1993.

BALCOMB, A. From Apartheid to the new dispensation. Evangelicals and the democratization of South Africa. Journal of Religion in Africa. Brill.Vol. 34, Fasc. 1/2 Feb. - May 2004, pp. 5 - 38.

BARUFFO, A. Riflessione teologiche sul movimento carismático. Civiltà Cattolica, Anno 125, 1974, Vol. $2^{\circ}$, 2794, p. 333.

BAUMAN, Z. - DESSAL, G. El retorno del péndulo: sobre psicoanálisis y el futuro del mundo líquido. Ciudad Autónoma de Buenos Aires: Fondo de Cultura Económica, 2014.

BEDIAKO, K. SocietyAfrica and Christianity on the threshold of the third Millennium. The religious dimension. African Affairs. Oxford University Press. Vol. 99, 2000, No. 395, pp. $303-323$.

BHABHA, H. Nuevas minorías, nuevos derechos. Notas sobre cosmopolitismos vernáculos. Buenos Aires: Siglo Veintiuno Editores, 2013.

BOESAK, A. Dare we speak of hope? Searching for language of life in faith and politics. Cambridge: W. B. Erdmans Publishing, 2014.

BORAINE, A. A country unmasked. Inside South Africa's Truth and reconciliation Commission. New York: Oxford University Press, 2000.

COMAROFF, J. Body of Power. Spirit of resistance. Chicago \& London: University of Chicago Press, 1985.

CZEGLÉDY, A. A new Christianity for a new South Africa. Charismatic Christians and the post-Apartheid order. Journal of Religion in Africa. Brill. Vol. 38, 2008, Fasc. 3, pp. 284 311.

DE GRUCHY, J. - VILlAVICENCIO, C. Apartheid is a heresy. Londres: D. Phillips, 1993.

DU TOIT, A. No chosen people: the myth of the calvinist origins of afrikaner nationalism and racial ideology. The American Historical Review. Indiana University, vol. 88, 1983, $\mathrm{N}^{\circ} 4$, october 19.

ELIAS, N. Society of Individuals. New York: Bloomsbury Publishing USA, 1983.

FOUCAULT, M. Genealogía del racismo. De la guerra de razas al racismo de Estado. Madrid: La Piqueta, 1992.

GLUCKMAN, M. Custom and conflict in Africa. Oxford y Cambridge: Blackwell, 1991. 
HEXHAM, I. Christianity and apartheid. The Journal of Theology for Southern Africa, No. 32, September 1980.

HORREL, M.; HORNER, D.; HUDSON, J. A survey of race relations in South Africa. Johannesburg: South African Institute of Race Relations, 1975.

KOSCHORKE, K. - SCHJøRRING, J. African Identities and world christianity in the twentieth century. Proceedings of the Third International Munich. Wiesbaden: Otto Harrassowitz Verlag, 2005.

MANA, K. Foi chrétienne, crise africaine et reconstruction de l'Afrique. Sens et enjeux des théologies africaines contemporaines. Nairobi: CETA, 1992.

MBEMBE, Achille. Necropolítica. España: Melusina, 2011.

PlaAtJiES VAN HUFFEll, M.; VOSLOO, R. Reformed Churches in South Africa and the struggle for justice: Remembering 1960-1990. Stellenbosch: African Sun Media, 2013.

PROZESKY, M.; DE GRUCHY, J. Living Faiths in South Africa. Cape Town: David Philip, Publishers, 1997.

TUTU, D. Dios no es cristiano, y otras provocaciones. Bilbao: Desclée de Brouwer, 2012.

VERWOERD, W. Towards the truth about the TRC. A response to key moral criticisms of the South African Truth and Reconciliation Commission. Religion and Theology. 6, 3, 1999, pp. $303-324$.

WALSHE, P. The Evolution of Liberation Theology in South Africa. Journal of Law and Religion. Cambridge University Press. Vol. 5, 1987, No. 2, pp. 299 - 311.

WESTHUIZEN, J. A democratic vision for South Africa: political realism and Christian responsibility. South Africa: Encounter, 1991.

WILSON, R. Reconciliation and Revenge in Post- Apartheid South Africa: Rethinking Legal Pluralism and Human Rights. Current Anthropology, vol. 41, 2000, N. 1, febrero.

WIREDY, K. Society and democracy in Africa. En: Teodros Kidros (Ed.) Explorations in African Political Thought. Londres - Nueva York: Routledge, 1988.

Sobre la autora

Eugenia Arduino. Doctora en el área de Historia por la Facultad de Filosofía y Letras de la Universidad de Buenos Aires; Posdoctoranda por la Universidad Nacional de Lomas de Zamora, Magíster y Especialista en Ciencias Sociales con mención en Historia Social por la Universidad Nacional de Luján; Profesora y Licenciada en Historia por la misma universidad. Se desempeña como Profesora e Investigadora en el Departamento de Historia, Facultad de Filosofía y Letras, Universidad de Buenos Aires, y en la División Historia, Departamento de Ciencias Sociales, Universidad Nacional de Luján. Es autora de libros y 
publicaciones científicas nacionales e internacionales; formadora de recursos humanos, participante en eventos académicos como organizadora, coordinadora y expositora, y evaluadora de proyectos de investigación. Sus líneas de investigación actuales: translocalización cultural afroasiática, y relaciones entre cultura, espacialidad y calidad de vida en contextos urbanos contemporáneos, especialmente en India y Sudáfrica. Correo
arduinoeugenia@gmail.com electrónico:

Recebido: 11.07 .18

Aprovado: 26.07 .18 